logical terms senescence does not follow an unbroken course.

Non-energistic formulæ do not appeal to the author. In fact he seems to delight in showing his antagonism toward them. For instance, he says that " attempts to connect particular facts with particular chromosomes or parts of chromosomes are not at the present, properly speaking, scientific hypotheses." This and similar statements leave no doubt as to the direction of Professor Child's interest. They may, unfortunately, keep some readers from a fair consideration of the very valuable results of his work.

The extent of the ground covered in the book is well indicated by the titles of the five parts. I. The Problem of Organic Constitution. II. An Experimental Study of Physiological Senescence and Rejuvenescence in the Lower Animals. III. Individualism and Reproduction in Relation to the Age Cycle. IV. Gametic Reproduction in Relation to the Age Cycle. V. Theoretical and Critical. About half of the space is devoted to the experiments of the author and the greater part of the observations appear here for the first time.

The importance of the facts and their general interest make it a matter for congratulation that they have appeared in this connected form rather than in separate papers. The book will be welcomed by all those interested in the problem of development.

\section{Charles Zeleny}

Land Magnetic Observations, 1911-1918 and Reports on Special Researches. By L. A. Bauer and J. A. Fleming. Washington, D. C., 1915. Publication No. 175, Vol. 2, of the Carnegie Institution of Washington. 4to. Pp. $v+278$. 13 plates, 9 text-figures. This is the second volume of the "Researches of the Department of Terrestrial Magnetism," the first volume having dealt with the magnetic observations on land from 1905 to 1910. Some idea of the magnitude of the work carried out under Dr. Bauer's energetic leadership can be gained from the statement that during the eight years following the founding of the department the various expe- ditions by land and sea covered in all nearly a million miles. Observations were made in 103 different countries and island groups. The results of these expeditions and of special investigations have been embodied in about 125 articles and publications. It is now expected that one of the chief objects for which the Department of Terrestrial Magnetism was founded, the general magnetic survey of the globe between latitudes $70^{\circ} \mathrm{N}$. and $65^{\circ} \mathrm{S}$., will be completed in 1916. Up to the present time this remarkable achievement has been accomplished without loss of life.

In view of the ever-changing values of the magnetic elements and of our imperfect knowledge of the secular variation in many parts of the earth, it is of immense importance in the analysis of the earth's magnetic field, and thereby ultimately to the navigator and surveyor, that magnetic data be secured for the whole globe at as nearly the same epoch as possible. As has often been remarked, we can never hope to know much about the magnetic field in a vertical direction above or below the earth's surface. Hence a minute and accurate knowledge of the magnetic field over the surface to which we are confined is of all the more importance. It will be greatly to the credit of the Carnegie Institution to have accomplished the task in less than a decade. No cooperation of civilized governments could be expected to do this. It is precisely in work of this sort that a richly endowed private institution can render its greatest service.

The first part of the volume is devoted to a description of instruments, with their corrections, and the magnetic standards finally adopted. Two new universal types of magnetometer have been developed by the department, and seven complete instruments have been constructed in the department's shop. Many persons not directly interested in magnetism would find it to their advantage to examine the ingenuity and elegance of some of the instrumental details.

The old-fashioned dip circle, with its eccentricities both literal and figurative, has largely given place to the earth inductor. Nothing is said about trouble from thermo-electric cur- 
rents in the use of the latter instrument, though due precautions must have been taken to avoid any possible error from this source. It is unfortunate that the Kelvin type of galvanometer still has to be retained, in most cases at least, on account of the stray field produced by the permanent magnet of the moving coil galvanometers. Dip values obtained with the earth inductor are now consistent to within about one minute of arc. The corrections for individual dip needles usually amount to very much more than this.

The tabulated results of observations are comprised in about forty pages. The data include geographical position, date, hour, and values of declination, dip, and horizontal intensity, for a very large number of stations in all of the continents, the antarctic regions, and chief island groups. No reduction of values to a common epoch is attempted. Intensities are given in C.G.S. units. Physicists may well question the necessity of introducing, at the headings of columns of horizontal intensity, the special symbol $\Gamma$, which, we are told, represents one C.G.S. unit. In the already highly be-symboled state of science would we not better rest content with that "perfectly good" name for the C.G.S. unit, which is also a reminder of the father of the science of terrestrial magnetism, the gauss?

In connection with the land observations, instrumental and other assistance has been furnished in cooperation with various organizations and expeditions. The Australasian Antarctic Expedition and the Crocker Land Expedition may be especially named. The observers' field reports are replete with notes of interest to the geologist, botanist, biologist and explorer. If one seeks information concerning selection of firearms, feeding of camels, defense against Bedawins, or canoeing in the Canadian wilderness, he will find it here.

A valuable feature of the book is the detailed description of the research buildings recently erected near Rock Creek Park. The main building is of fireproof construction, and so stable that no perceptible vibration is transmitted to the most sensitive galvanometers, even when the machinery in the basement is running. For work demanding freedom from magnetic disturbances, a separate non-magnetic building has been erected. Those interested in the building and equipment of laboratories of any kind will profit by a study of these carefully planned structures.

The only special researches recorded in this volume are some miscellaneous observations made in Samoa at the time of the solar eclipse of April 28, 1911, and a very detailed description of the comparisons of magnetic standards made at various observatories. The present attainable precision in magnetic observations may be learned from the statement that "the corrections, on absolute standards, for the declination and inclination may be in error by $0^{\prime} .1$ or $0^{\prime} .2$ and for the horizontal intensity by about $0.0001 H . "$

$$
\text { W. G. CADY }
$$

WESLEYAN UNIVERSITY

\section{SPECIAL ARTICLES}

\section{SOME SUGGESTIONS ON METHODS FOR THE} STUDY OF NITRIFICATION

DURING recent years the use of one gram of dried blood, tankage, cotton-seed meal, bone meal, etc., mixed with $100 \mathrm{gm}$. of soil, has commonly been employed in laboratory studies on nitrification. In some cases as much as 2 per cent. of these materials has been used. On the other hand, a much smaller amount of ammonium sulfate is usually added because of its greater solubility and recognized toxicity to the nitrifying organisms when present in excessive concentrations. The results are frequently stated in terms of the absolute amounts of nitric nitrogen formed rather than in percentages of nitrogen nitrified. Comparisons and conclusions on the relative nitrifiability of nitrogenous fertilizers are commonly made on the basis of evidence obtained in this way.

In the course of studies on nitrification at the University of California Citrus Experiment Station, the writer recently observed a wide range of variation in the nitrification of

1 Paper No. 20, Citrus Experiment Station, College of Agriculture, University of California, Riverside, Calif. 